\title{
Setting the Stage for Creative New Products: Investigating the Idea Fruition Process
}

\author{
Janice Griffiths-Hemans
}

Astra Zeneca

Rajiv Grover

University of Georgia

This article attempts to understand the idea fruition process, or the fuzzy front-end set of activities that an organization may informally engage in before it adopts a formal process for developing a new product. The authors propose that the idea fruition process consists of three subprocesses: idea creation, idea concretization, and idea commitment. They also propose and test the individual and organizational factors that influence the idea's degrees of creativity, concretization, and commitment to further the understanding of the phenomenon and, thus, boost the creation and harnessing of worthwhile ideas in organizations.

Keywords: idea fruition process; creativity; informal new product development

The current, fierce competitive environment demands that companies achieve a fast pace of successful innovations. Although considerable progress has been made in formalization of efficient new product development (NPD) processes (Sethi, Smith, and Park 2001), researchers have argued that this is perhaps just half the battle. To be completely innovative, companies must successfully create an environment that informally nurtures the generation and growth of ideas (Kanter, Kao, and Wiersema 1997). The informal basis of idea generation and idea development, which we refer to as the idea fruition

Journal of the Academy of Marketing Science.

Volume 34, No. 1, pages 27-39.

DOI: $10.1177 / 0092070305281777$

Copyright $₫ 2006$ by Academy of Marketing Science. process, or the "fuzzy front end" of NPD, can, should, and does occur even though formal processes may be in place (Bhardwaj, Grover, and Madhavan 2005; Cooper and Kleinschmidt 1986; Khurana and Rosenthal 1998). According to Crawford (1994), these critical informal activities are not well understood. In an effort to understand the idea fruition process better, Bhardwaj et al. (2005) explored the role of informal social networks. They argue that significant NPD activities may be conducted and milestones may be achieved informally by individuals before the organization's formal commitment (e.g., in terms of resources and development of time line) to NPD. This individual-level informal activity of idea generation and development is the focus of this article.

Given the importance of the idea fruition process, the goal of this article is to comprehend further the process so that organizations can better grasp the individual- and organizational-level factors that influence the informal generation and harnessing of new product ideas. The three primary questions of interest pertaining to the idea fruition process that we address herein are as follows: what individual characteristics and organizational factors influence (1) the creativity level of ideas that an individual generates, (2) the informal development of the creative ideas, and (3) the organization's formal commitment to convert the ideas into new products? Our addressing these questions will enable organizations not only to prevent creative, nascent, and potentially profitable ideas from dying prematurely but also to create proactively an environment that will stimulate such creation and harnessing of ideas. From a theoretical perspective, this article proposes a critical subprocess within the idea fruition process, resulting in 
a normative model of managing the idea fruition process for optimal effectiveness and efficiency.

The model of the idea fruition process that we develop uses a grounded theory approach of integrating literature with data from qualitative research (Glaser and Strauss 1967). Because little is known about the idea fruition process, we believed that qualitative research could be useful in identifying both variables that are central to the idea fruition process and variables that influence it. In addition, a cursory review of the creativity literature revealed that there were hundreds of variables investigated. Qualitative research with relevant practitioners and applicationoriented case studies would enable us to identify which among the hundreds of variables would be useful for the idea fruition process. An iterative process that went back and forth between academic literature and interviews and case studies resulted in a final model that we empirically tested.

The remainder of this article is structured as follows: First, we provide a brief overview of the qualitative methodology used to collect and analyze data. Second, on the basis of the NPD and creativity literature and the data collected during the qualitative research, we develop the model of, and propositions for, the idea fruition process. Third, we discuss the empirical method we used to test the model, and we provide the results and their discussion. Last, we offer managerial implications and provide directions of future research.

\section{QUALITATIVE RESEARCH}

Given the vast amount of literature in the field of creativity from diverse disciplines, we found hundreds of variables that influence creativity. However, we could not glean much about the idea fruition process from the literature, nor could we surmise much about the potential set of important variables that could influence the idea fruition process. Thus, we conducted qualitative research using two methods, case research and in-depth interviewing.

\section{Qualitative Research Methodology 1: Case Analysis}

We developed case studies on innovative and breakthrough products in the twentieth century from published material that documented the history of these products. We selected products that Nayak and Ketteringham (1986), Yenne and Grosser (1993), and Golder and Tellis (1993) cited as candidates for case studies along with other products that were launched subsequent to the publication of these three articles. This procedure resulted in a range of products - from end user products and services to technologies and processes-that had varying degrees of ultimate success. We considered material from the moment of inspiration to the organizational commitment relevant if it discussed at least one of the following three areas: (1) background of the idea originator; (2) organizational culture, structure, and strategic framework at the time of idea conceptualization; and (3) initial conceptualization of the idea. Requisite material for 12 cases studies was available, which is in line with Eisenhardt's (1989) recommendation of the optimal number for case-based research. The products used in the case analysis were as follows: adhesive for Post-it Notes, Post-it Notes, Oak (precursor to Java), Jini, velcro, microwave oven, nylon, Teflon, running shoes (Nike), photocopier machine, frozen dinners, and walkman. Three judges objectively and systematically contentanalyzed these materials at the theme level as Kassarjian (1977) outlined to ensure triangulation and increase the reliability of the analysis (Patton 1990). To aid in crosscase comparisons, we wrote product scenarios using a question-and-answer format (Yin 1994). Questions used to guide product scenarios were as follows: (1) What factors influenced the creation of the idea? (2) What factors influenced the nurturing and organizational harnessing of the idea? and (3) What is the status of the idea?

\section{Qualitative Research Methodology 2: In-Depth Interviews}

We conducted semistructured in-depth interviews with idea originators and individuals who were involved with the development and filtering of new product ideas. We took care to ensure that the interviewees covered the topics of interest and that they used their own words to describe the idea fruition process. We conducted 23 in-depth interviews that lasted approximately 40 minutes each. Half of the sample consisted of interviews with individuals who were the idea originators, and the other half consisted of individuals who were responsible for evaluating the ideas and making decisions about their further development. Respondents for the in-depth interviews were from both small start-up firms and more established ones, and they represented a cross section of industries (e.g., consumerpackaged goods, high technology, telecommunications, pharmaceuticals). All idea originators but one were in research and development (R\&D) or product development, and all were engineers or scientists by training.

\section{CONCEPTUAL MODEL AND PROPOSITIONS}

A key contribution of the qualitative research on the idea fruition process was the development of a central phenomenon that we label the idea concretization subprocess. The other two subprocesses that precede and follow the 
idea concretization subprocess, respectively, are (1) the process of idea creation and (2) the process of obtaining commitment from management for formal development of the idea into a product.

In the idea creation phase, an individual comes up with a product idea. According to Nayak and Ketteringham (1986), a product idea can be defined as a mental picture or "elegant concept" of a possible and feasible solution to a problem. After the individual has conceptualized the idea, he or she works to develop it. If it occurs, such development can take several paths. In a not-so-effective idea fruition process, the development of the idea is typically in the direction of a product prototype. In a more efficient idea fruition process, our qualitative research revealed that the individual focuses on developing the concept, with or without the help of others in the organization, with the goal of making it acceptable to influential internal stakeholders. For example, the marketing group might not want to see a version of the prototype but rather might want to determine how the concept satisfies certain unfilled needs of a segment. Concretization for the marketing group means that the concept is developed such that certain attributes that are desired by a targeted segment are made available in the product. In other words, the conceptual model of the product with the complete positioning is more appealing to the marketing group than are specific components of the product. Furthermore, the manufacturing group might want to ensure that the organization has the requisite competencies to build such a product. Thus, this group wants to determine what it would take to make the product. Other $R \& D$ scientists might want the product to develop in a way that validates the critical technical assumptions. Development of the concept on all relevant dimensions is the notion of concretization.

The literature has identified the constructs of framing and issue selling. According to McKenzie (2003), framing effects occur when "equivalent redescriptions of objects lead to different judgments" (p. 330). Dutton and Ashford (1993) defined issue selling as the "process by which individuals affect others' attention to and understanding of the events, developments, and trends that have implications for organizational performance." Concretization is more than framing and issue selling, although it may involve both. Whereas issue selling focuses on the process of how to sell, concretization implies the "what" of selling. Dutton, Ashford, O'Neill, and Lawrence (2001) pointed to packaging as one of the variables that influence the success of issue selling. Our notion of the term concretization is more than mere packaging. In other words, in the idea concretization phase, the product idea may be given several "faces" or "forms," each of which is a facet of the potential new product, for the purposes of convincing and selling to the key stakeholders. Concretization includes development, but if development of the concept occurs, it does so with the goal of making the idea acceptable rather than the goal of progressing toward a prototype per se.

Finally, for the organization to take advantage of the concretized product idea, it must formally accept it and commit resources to developing it into a product. Thus, the third subprocess in the idea fruition process is the idea commitment phase.

The output of the idea creation stage is a creative idea. However, the degree of creativity of the idea can vary from situation to situation. The output of the concretization phase is a blueprint, a plan, a design, a prototype, and so forth. The degree of concretization varies depending on the idea, the idea originator, his or her interaction with colleagues, and the organization. Finally, the output of the commitment phase is organizational commitment to formally develop the product. Organizations can vary in their support for new product ideas. Hence, the three dependent variables we use herein to capture the output of the three phases, respectively, are degree of creativity, degree of concretization, and degree of commitment. Individual idea originators and organizational factors both influence the degrees of creativity, concretization, and commitment.

\section{Idea Creation Stage}

The marketing literature (e.g., Andrews and Smith 1996; Menon, Bharadwaj, Adidam, and Edison 1999) has identified many variables that influence creativity of marketing programs and strategies. We build on these variables and identify several other individual-level and organizationlevel variables and study their influences on the creativity level of an idea.

Expertise. Andrews and Smith (1996) identified both knowledge of the environment and diversity of experience and education as variables that influence creativity. Related to these variables, we conceptualize expertise as an overall construct that influences creativity. That is, for an individual to come up with a solution to a problem, he or she must have some knowledge of, and skills in, the problem domain. Although creative solutions sometimes are unexpected occurrences or findings, the ability to recognize a potential creative idea when an accident occurs still requires domain-relevant skills (Amabile 1983). As the complexity of the domain of the problem increases, a greater amount of domain-relevant knowledge and skills is required. Domain-relevant knowledge and skills are a person's ability, defined by his or her technical, procedural, and intellectual knowledge, in that task or problem domain. Such skills are influenced by formal and informal education, innate cognitive abilities, and perceptual and motor skills (Amabile 1983; Simon 1986). Individuals who exhibit both depth and breath of such skills are considered experts in their area. 
However, Stein (1989) and Csikszentmihalyi (1990) cautioned that depth of knowledge can inhibit individuals from deviating from the norm and existing paradigms because expertise is frequently derived through routinization. Bereiter and Scardamalia (1993) attempted to resolve this debate by suggesting that if experts remain at the boundaries of their knowledge, where they operate as nonexperts, they are more likely to be creative in problem solving. The notion of experts operating as nonexperts implies the continuous expansion of the knowledge base, keeping abreast of changes and advances in the knowledge domain, and the questioning of existing assumptions.

Experts tend to have breadth of knowledge as well. Breadth increases the chances of a creative idea occurring or enhances the creativity of the idea because it adds to the individual's ability to "bisociate" (i.e., connect previously unconnected matrices of experiences) (Koestler 1964) or because it increases an individual's intellectual space for exploration and problem solving (Amabile 1998). Deep knowledge in these supplemental domains is not necessary, but a working knowledge is (Madhavan and Grover 1998). Depth and breadth of knowledge as components of expertise are hallmarks of an expert. Thus,

Hypothesis 1: As the level of the idea originator's expertise increases, the degree of creativity of the generated idea increases.

Thinking style. Amabile (1983) identified creativityrelevant skills as important in a person's ability to be creative. Included in the set of creativity-relevant skills is a person's thinking style. Creative thinking involves using incomplete guidelines of heuristics rather than logical methods of algorithms (Amabile 1983; de Bono 1971; Koestler 1964; Moore 1969; Rossman 1964; Simon 1986; Sternberg and Lubart 1991). Creative thinking is considered lateral thinking rather than a logical way of thinking, which is sometimes referred to as "vertical thinking." Lateral thinking entails asking what-if questions to generate from new perspectives many alternatives to an issue and involves looking for what is different. Thus, we propose the following:

Hypothesis 2: As the idea originator's thinking style becomes more lateral or less vertical, the degree of creativity of the generated idea increases.

Work style. A person's work style is another creativityrelevant skill. Two factors that enhance creativity have been identified in this domain: incubation and isolation. Incubation is the point at which the individual turns away from the problem at hand and allows the subconscious to find a solution (Rossman 1964; Young 1960). By stepping away from a problem, a person has been known to come up with a solution in a flash or a fleeting moment. During this period, people undergo a period of "masterful idleness" (e.g., taking walks, sleeping, engaging in other tasks). Although the incubation period could take days or years, intense mental concentration and searching occurs subconsciously during this period. At the point at which a person reaches a solution, it is brought to the conscious mind in a flash.

Isolation of an individual from others can also increase his or her ability to come up with a creative idea. Zajonc (1965) suggested that an "audience effect" makes it difficult for people to engage in novel tasks in front of others. This audience effect causes increased anxiety and excitement, which results in a narrowing of attention. The individual may need to be isolated in order to separate himself or herself from the ruling assumptions and the judgment of others. ${ }^{2}$ Thus,

Hypothesis 3: As the level of appropriate work style engaged in by the idea generator increases, the degree of creativity of the generated idea increases.

Failure value. Failure value is the set of benefits/losses that an individual associates with failing at a task or experiment. Gaining experience from prior failures is often essential before a breakthrough can occur (Moore 1969; Rossman 1964). Failing also enables an individual to learn what does and does not work (Amabile 1998). Consequently, as the benefits to failing (i.e., the sense of failure value) increase, an individual should be more willing to engage in trial-and-error activities that result in creative ideas.

Hypothesis 4: The greater the sense of failure value, the greater is the degree of creativity of the generated idea.

Intrinsic motivation. Intrinsic motivation is the final individual-level variable that we include as a key for creativity. ${ }^{3}$ It is the motivation to engage in work primarily for its own sake because the work itself is interesting, engaging, or in some way satisfying (Amabile, Hill, Hennessey, and Tighe 1994; Andrews and Smith 1996; Nayak and Ketteringham 1986; Ruscio, Whitney, and Amabile 1998). Many product breakthroughs have come from individuals who focused primarily on solving a problem rather than on seeking fortune or exploiting markets (Nayak and Ketteringham 1986). Thus,

Hypothesis 5: The greater the idea originator's intrinsic motivation for the task, the greater is the degree of creativity of the generated idea.

Formal organizational culture. An organization's culture is the value system that an individual perceives as being promoted by the organization (Deshpandé and Webster 1989; Menon et al. 1999; Moorman 1995; 
Smircich 1983). If the values that the organization purports do not support innovation, an individual will find it difficult to be creative. Organizational culture can be roughly categorized as either formal or informal (Smircich 1983). The formal aspects are the systems and processes that are in place and are publicized as such. Informal culture is the unspoken but practiced methods of what and how activities are encouraged and executed. With regard to innovation, we identified four aspects of the culture domain: access to relevant and diverse knowledge, access to resources, rewards for innovation, and allowing time for new ideas. We present the first two dimensions as being under the umbrella of informal culture because they involve cooperation from others on a volunteer basis (e.g., the organization has not yet formally approved the project for funding, nor has it asked others to contribute to the project). We do not expect informal culture to influence creativity, although we expect formal culture to do so.

Through their policies, many organizations encourage individuals to engage in trial-and-error experimentation for the purpose of creating new ideas. The policies allow individuals to spend company time on new ideas and also reward them for successful ones. Therefore, we incorporate the time and rewards aspects under the formal organizational culture construct. The sanctioned availability of rewards and time (or the formal organizational culture) can affect the desire of the individual to engage in creativity. Thus,

Hypothesis 6: The more the formal organizational culture supports innovation, the greater is the degree of creativity of the generated idea.

\section{Idea Concretization Stage}

In the organizational context, concretization of an idea should ensure that there is a fit among end users, technology, and strategy. This criterion is generally established by organizations to ensure that creativity at the individual level is in line with organization-level creativity (Woodman, Sawyer, and Griffin 1993). Given this criterion, the idea originator may not have all the requisite knowledge for concretization and, thus, may require help from other individuals within the organization. For such cooperation to prevail in the organization, both formal and informal aspects of organizational culture should be conducive. We previously discussed the formal organizational culture for the purposes of innovation. The informal components for facilitating innovation are access to relevant and diverse knowledge and access to organizational resources. In addition, to seek involvement of other organization members, the idea originator must continue to be intrinsically motivated and have the requisite credibility with them.
Credibility. Credibility is the perception of and regard for the inventor within and by the organization. Credibility in the context of NPD is based on expertise, prior performance, power, and trustworthiness (Joseph 1982; Kahle and Homer 1985). If the idea originator is not considered an expert, colleagues will be hard-pressed to contribute time and energy to the idea. If the idea originator has a reputation for innovative new products, it is more likely that the informal organization will help concretize the idea. Credibility may also arise as a result of the individual's position of authority within the organization. In such a case, power due to the position itself may be enough to generate cooperation. Finally, if colleagues do not trust the idea originator and, thus, do not recognize his or her contributions, they will be inclined not to help the idea originator. Thus,

Hypothesis 7: The greater the idea originator's credibility, the greater is the degree of concretization of the generated idea.

Intrinsic motivation. The impact of intrinsic motivation on creativity is well documented in the literature, as we previously discussed. Intrinsic motivation should also have an influence on the degree of concretization. Concretization involves more detailed work from the idea generator as well as causes him or her to request help from other members of the organization. It also involves garnering resources. If the idea originator does not have the motivation to persevere in these areas, concretization might not be possible. Thus,

Hypothesis 8: The greater the idea originator's intrinsic motivation, the greater is the degree of concretization of the generated idea.

Formal organizational culture. At the idea concretization stage of the idea fruition process, organizational support plays an important part in the eventual success of the idea. As we discussed previously, the requirements to concretize the idea may be wide-ranging and diverse. The product idea is at an infantile stage and is being "pushed" mostly by the idea originator. Thus, individuals' knowing that the organization supports their expending time for innovation and that rewards are in place for success will affect the level of cooperation across departments (Griffin and Hauser 1996; Gupta, Raj, and Wilemon 1986; Holt 1988). Thus,

Hypothesis 9: The more the formal organization's culture supports innovation, the greater is the degree of concretization of the generated idea.

Access to relevant and diverse knowledge. It has been argued that an individual's expertise reflected by the depth and breadth of knowledge is important in the idea creation 
process. However, in the idea concretization phase, the idea originator's expertise by itself may not be sufficient. Many more details must be wrestled with in this phase, including development of new technology, manufacturing, supply sources, understanding of customer needs, and so forth. Because of the varied knowledge needs, the idea originator's access to a relevant network of knowledge both within and outside the organization is important (Bhardwaj et al. 2005; Madhavan and Grover 1998). Informal social interactions can yield benefits that are similar to those from formal groups. The more interactions the individual has across diverse domains, the more likely the creative idea will be concretized. An organization's informal culture allows for or inhibits such interactions among individuals. Thus,

Hypothesis 10: The greater the access to relevant and diverse knowledge, the greater is the degree of concretization of the generated idea.

Access to organizational resources. Availability of resources influences an individual's ability to concretize his or her idea. Typically, the lone inventor must find and use his or her own resources (Rossman 1964). However, if an organization makes its resources available to the individual engaging in "experimental doodling" (Collins and Porras 1994), it increases the individual's chances of concretizing creative ideas. Some organizations, such as $3 \mathrm{M}$, provide informal organizational support by "stipulating" that employees can use resources for personal projects (Collins and Porras 1994). Although the organization may permit individuals to use its resources for personal projects, this does not signify formal commitment to, or interest in, the individual's project. Rather, it demonstrates the organization's belief in learning and experimentation, and it guarantees that the organization will not interfere with or evaluate employees' pursuits. Thus,

Hypothesis 11: The greater the access to organizational resources, the greater is the degree of concretization of the generated idea.

\section{Idea Commitment Stage}

At the point at which one or more product blueprints or plans are developed, the creative idea is concretized, and the phase of seeking commitment from top management/ decision makers begins. This process ends in the organization deciding to formally pursue the development of the new product or not. The degree of organization involvement is restricted to evaluation of the blueprints, plans, and so on, and ironing out of the problems if needed. The idea can be rejected and sent back to the drawing board, but this is tantamount to the organization not committing to the idea (Woodman et al. 1993). Literature and the qualitative research suggest that presence of an idea visionary, credibility of the idea originator, organizational consequences of creation, and the formal organizational culture all affect an organization's decision to commit to furthering the development of a product blueprint.

Idea visionary. Innovations need leadership by committed enthusiasts to overcome the organization's vested interest in stability and the status quo (Grant 1995). As such, an inventor may need the help of others (i.e., idea visionary) to develop and communicate the benefits and potential of the concretized idea and to increase the likelihood of its acceptance into the formal NPD process. As in the formal NPD process in which a product champion takes an inordinate interest in ensuring that a particular process or product is fully developed and marketed, at the idea fruition stage, the idea visionary informally accepts the responsibility of promoting the idea to the stakeholders to seek commitment. An idea visionary is typically a person of power or authority within the organization. An idea visionary seeks to encourage the organization to invest in the idea by breaking down resistance that may be due to conservatism and political agendas or to the short-term orientation inherent in individuals and organizations (Grant 1995; Van de Ven 1986). An essential difference between an idea visionary and a product champion, as some respondents alluded, is the degree to which the individual supports the idea or product. A product champion is expected to overcome internal hurdles, but if unexpected and negative changes occur in the marketplace, he or she would recommend abandoning the development if necessary. Conversely, the idea visionary supports the idea from a 10,000-foot level. A no-go decision is not necessarily part of the idea visionary's responsibility. In addition, a product champion can mandate institutional resources and personnel to cooperate. In contrast, an idea visionary can use his or her social capital and personal credibility at best. Thus,

Hypothesis 12: The greater an idea visionary's influence, the greater is the degree of commitment for the concretized idea.

Credibility. As with the idea concretization process, the greater the credibility of the idea originator in the organization, the greater is the level of commitment from the organization. The logic is the same as previously, and therefore, to save space, we do not repeat it here.

Hypothesis 13: The greater the idea originator's credibility, the greater is the degree of commitment to the concretized idea.

Consequences of creation. New products induce organizational changes (Moore 1969; Woodman et al. 1993). An innovation could affect the interaction among technol- 
ogy, manufacturing, marketing, and other organizational functions (Grant 1995; Lynn, Mazzuca, Morone, and Paulson 1996). Chandy and Tellis (1998) claimed that the more the specialized investments the firm has, the less they are willing to cannibalize. In the context of the idea fruition process, the consequence of creation is the perceived level of organizational change demanded by the concretized idea. The greater the change to its status quo an organization perceives it may have to make, the less likely it will be to endorse the concretized idea. An organization may be more comfortable with ideas that are based on adapting preexisting products or processes rather than on endorsing breakthroughs or ideas that are based on new technology or paradigms.

Hypothesis 14: The lesser the perceived negative consequences of creation, the greater are the degree of commitment for the concretized idea.

Formal organizational culture. Support of a formal organizational culture for innovation has a direct effect on the degrees of creativity and concretization by motivating involved individuals. We define formal organizational culture as the degree to which individuals are allowed time to experiment and are rewarded for successful efforts. This should not directly influence top management's/decision maker's propensity to support the project. However, having these characteristics in place is reflective of management's attitude toward innovation. Formal organizational culture can then be considered a surrogate of management's attitude toward innovation. Such an attitude would imply that the organization is not risk averse and will not tend to avoid committing to new product ideas. Such organizations are comfortable with new ideas (Collins and Porras 1994). However, because informal organizational culture is not directly under top management's control, it could be contended that it is not the best indicator of management's attitude, and thus we do not include it as one of the variables that might affect the degree of commitment. Thus, insofar as formal organizational culture is a proxy for management's positive attitude toward innovation, we posit the following:

Hypothesis 15: The more the formal organization's culture supports innovation, the greater is the degree of commitment to the concretized idea.

The preceding discussion highlights 11 variables that influence the idea fruition process. Of these 11 variables, 6 (expertise, thinking style, work style, isolation, failure value, intrinsic motivation, and credibility) are individuallevel variables, and 5 (formal organizational culture, access to relevant and diverse knowledge, access to organizational resources, visionary, and consequences of creativity) are organizational variables. Figure 1 shows the overall model.

\section{FIGURE 1 Factors Influencing Creativity, Concretization, and Commitment}

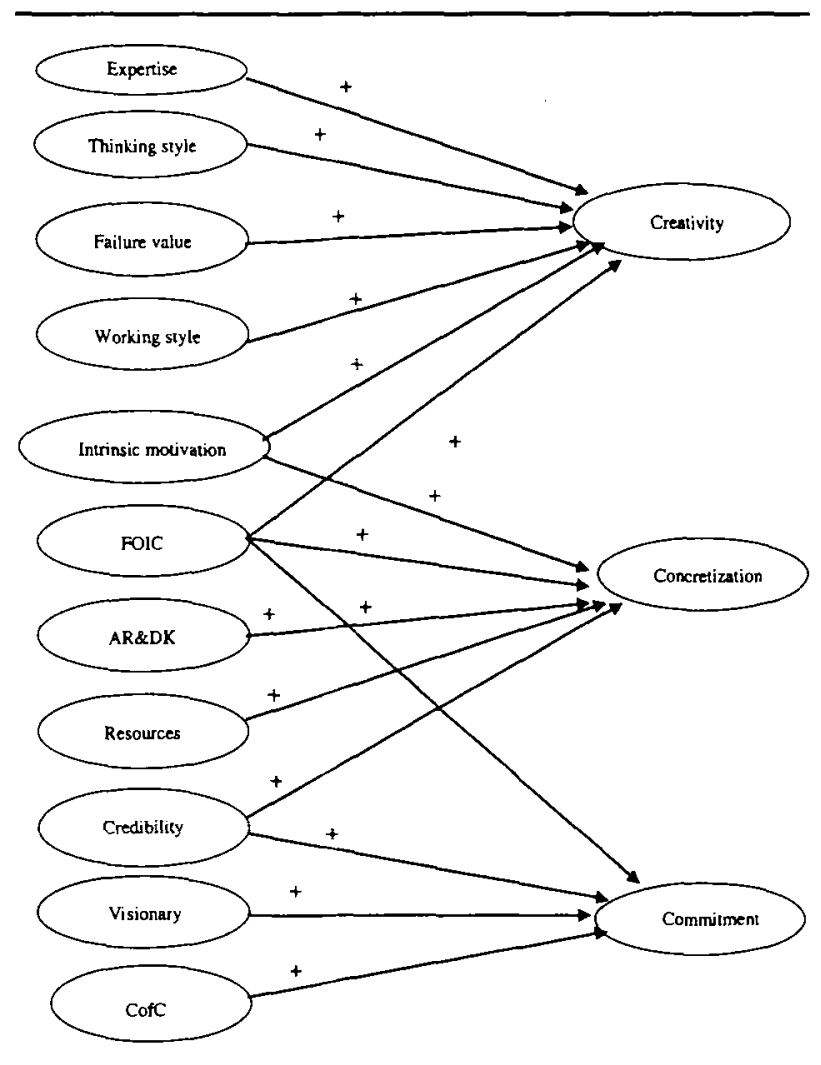

NOTE: FOIC $=$ formal organizational culture; $A$ R\&DK $=$ access to relevant and diverse knowledge; $\mathrm{CofC}=$ consequences of creativity. Signs show the hypothesized direction.

\section{EMPIRICAL METHOD}

The scales we used in this study either were newly developed for this research or were modifications of existing scales. To save space, we do not mention all the scales that we reviewed from the literature. However, some of the scales we used with marginal modifications include thinking style (Sternberg 1985), work style (incubation and isolation; Holland and Baird 1968), culture (Andrews and Smith 1996; Menon et al. 1999), intrinsic motivation and rewards (Amabile et al. 1994; Andrews and Smith 1996), and creativity (Menon et al. 1999). We used qualitative research to develop scales of other constructs that were not completely discussed in the literature. In addition, we used qualitative research to articulate both the dimensions of the construct and the words and terms used in the items. On the basis of the literature and qualitative research, we conceptualized the independent variables as formative scales and the dependent variables as reflective scales. For the formative scales, we took care to include all the relevant subspaces. For example, expertise consisted of real 
aspects, training and experience, and perceptual opinions; thinking style consisted of lateral and vertical thinking; formal culture consisted of rewards and time; and so on.

When we pretested the questionnaire and interviewed practitioners, it was revealed that developing a multi-item scale for degree of commitment was difficult and not necessary. Moreover, we found that it was difficult for idea originators to say more than just whether the idea was committed to or not. This was due to the clear go/no-go decision that they needed to make. Thus, we constructed degree of commitment as a single-item trichotomous variable, only to dichotomize it eventually.

We conducted a survey of individuals who had had a creative idea to test the propositions in the conceptual model. We identified these idea originators using two sampling frames. The first sampling frame was based on two industry segments-factory automation and telecommunications and Internet-in the CorpTech Directory of Technology Companies. The second sampling frame was from the Society of Manufacturing Engineers (SME) and consisted of a database of 3,000 names and addresses of individuals who indicated their job function as in R\&D or product design.

The two industries we chose in the CorpTech database provided a mixture of $R \& D$ and manufacturing-driven companies and included 14,027 operating units of public and private high-technology firms. We selected companies that had identified a contact person in R\&D or engineering and had at least $\$ 50$ million in sales revenue. After we removed duplicate names and names of presidents and chief executive officers, 910 usable names remained. The $R \& D$ and engineering individuals were contacted by telephone to identify an idea originator. We identified a net of 363 leads for idea originators from this database.

The SME database provided 2,753 usable names after the names that were already available from the CorpTech database were removed. Because the SME database did not include telephone contact numbers, the questionnaire was mailed to all.

\section{RESULTS}

Of the 363 leads from the CorpTech sample, 198 (55\%) refused to participate, and 165 (45\%) agreed. Reasons for not participating included "not interested," "against company policy," and "company does not generate ideas for new products, but manufactures products instead." All 165 individuals who agreed to participate were sent the questionnaire by e-mail, fax, or mail, depending on the respondent's preference. Most respondents preferred to receive the questionnaire by e-mail. Reminders were sent after one-and-a-half weeks and then again after a week. Of the
165 respondents who received questionnaires, 72 (response rate $43.6 \%$ ) completed and returned them. Reasons for withdrawing included "job reassignment," "no longer have time to complete the survey owing to recent developments within the company," or "do not find the survey relevant."

Of the 2,753 questionnaires mailed to the individuals in the SME database, 72 surveys were completed and returned. The response rate is difficult for us to calculate because not all of the people listed in the database could have originated an idea. The two frames provided a total sample of size 144 .

Table 1 provides the descriptive statistics for the variables and the correlations among the continuous variables. All the correlations between the independent variables are not large, thus reducing our concern about multicollinearity. ${ }^{4}$ Table 2 provides information on the scale items and whether the constructs are conceptualized as formative or reflective. The individual items within each construct are different enough so as not to be purely reflective of the construct. We conceptualized the dependent variables as reflective, and we report Cronbach's alphas. Both creativity and concretization have an acceptable level of reliability (.78 and .75 , respectively). We constructed all the scales with at least three items.

Table 3 summarizes the results for the three dependent variables. ${ }^{5}$ For the degree of creativity as the dependent variable, the adjusted $R^{2}$ is .22; expertise, thinking style, failure value, and intrinsic motivation are significant and in the hypothesized direction. Work style and formal culture are insignificant. A possible explanation for the insignificant result for work style could be that both incubation and isolation are difficult to practice in an organizational setting. Perhaps incubation is more relevant for deep scientific discoveries and inventions, something in which our respondents were not necessarily engaged. Similarly, isolation may be difficult in an organization. More important, however, given that ideas are concretized with others' help (e.g., access to relevant and diverse knowledge, idea visionary), respondents might have been confused about the stage in which isolation was practiced or not.

However, the situation with formal organizational culture is potentially notable. Although insignificant, the variable is negative; this result caused us to seek an explanation through the literature. The evidence in the literature points to the importance of providing appropriate rewards to the inventor, because some rewards may be viewed as bribes and, thus, might dissuade the inventor from pursuing his or her idea (Amabile 1998; Rossman 1964). It may be that the elements considered in this variable are tantamount to inappropriate rewards. However, this variable is positive and significant, as hypothesized for the other two dependent variables. In terms of idea concretization, typically other individuals within the organization become 
TABLE 1

Descriptive Statistics and Correlations ${ }^{\mathrm{A}}$

\begin{tabular}{|c|c|c|c|c|c|c|c|c|c|c|c|c|c|}
\hline Variable & 1 & 2 & 3 & 4 & 5 & 6 & 7 & 8 & 9 & 10 & 11 & 12 & 13 \\
\hline 1. Expertise & $\begin{array}{c}5.59 \\
(1.20)\end{array}$ & & & & & & & & & & & & \\
\hline 2. Thinking style & -.14 & $\begin{array}{c}3.57 \\
(.94)\end{array}$ & & & & & & & & & & & \\
\hline 3. Failure value & .03 & .08 & $\begin{array}{c}4.74 \\
(1.17)\end{array}$ & & & & & & & & & & \\
\hline 4. Working style & -.07 & .09 & .03 & $\begin{array}{c}4.15 \\
(.98)\end{array}$ & & & & & & & & & \\
\hline 5. Intrinsic motivation & .13 & .11 & .03 & .38 & $\begin{array}{c}4.38 \\
(1.25)\end{array}$ & & & & & & & & \\
\hline 6. Credibility & .71 & -.06 & .13 & .21 & .33 & $\begin{array}{l}5.59 \\
(.99)\end{array}$ & & & & & & & \\
\hline 7. Formal organizational culture & .16 & .08 & .15 & -.03 & .11 & .25 & $\begin{array}{c}4.33 \\
(1.10)\end{array}$ & & & & & & \\
\hline 8. Access to relevant and diverse knowledge & -.00 & .20 & .34 & -.25 & .04 & .11 & .27 & $\begin{array}{c}4.82 \\
(1.11)\end{array}$ & & & & & \\
\hline 9. Access to resources & .21 & .17 & .31 & -.03 & .21 & .31 & .35 & .36 & $\begin{array}{c}4.69 \\
(1.43)\end{array}$ & & & & \\
\hline 10. Idea visionary & -.02 & .18 & .06 & -.67 & .21 & .16 & .14 & .34 & .07 & $\begin{array}{c}3.85 \\
(1.24)\end{array}$ & & & \\
\hline 11. Consequences of creation & -.11 & .10 & -.03 & .10 & .04 & .02 & -.05 & .14 & -.17 & .23 & $\begin{array}{c}3.64 \\
(1.28)\end{array}$ & & \\
\hline 12. Creativity & .10 & .40 & .15 & .15 & .25 & .12 & -.04 & .04 & .06 & .06 & .26 & $\begin{array}{l}5.70 \\
(.89)\end{array}$ & \\
\hline 13. Concretization & .14 & .12 & .25 & -.10 & .06 & .18 & .32 & .46 & .37 & .35 & -.03 & -.07 & $\begin{array}{c}4.83 \\
(1.16)\end{array}$ \\
\hline
\end{tabular}

a. Main diagonal $=$ mean $($ standard deviation $)$; lower triangle $=$ correlations.

involved. Individual factors such as thinking style, work style, and intrinsic motivation are not necessarily the forces behind others' involvement. Rather, other individuals are likely to be motivated by how the idea affects them, and thus such rewards may not be deemed as inappropriate. In the case of idea commitment, the logic of formal organizational culture as reflective of top management's attitudes toward innovation is valid and not marred by the perceived inappropriateness, as it is in the case of idea creation.

The results for degree of concretization show that all the organizational factors are significant, as we hypothesized. Both the individual factors credibility and intrinsic motivation of the idea creator are not significant. The adjusted $R^{2}$ of .27 is the highest of the three dependent variables and, to some degree, points to the legitimacy of the overall conceptualization of the idea fruition process. Although we hypothesized that the idea originator must be intrinsically motivated to continue the process of concretization and must have credibility to involve others, it seems that these individual variables are not as important as the other organizational variables for concretization.

Table 3 also provides the results for the degree of commitment. All the variables are significant in the logistic model, with the Cox and Snell $R^{2}$ of 17 .

\section{Relationship Between the Three Dependent Variables}

As we show in the correlation matrix, the correlation between creativity and concretization is small $(-.07)$. Although on the surface it seems that this relationship should be positive, the reason it is not may be that more creative ideas require more concretization, but organizations may not actually achieve that level of concretization. That is, less creative ideas may be easier to concretize. It is the actual level of concretization that we measure herein, not the appropriate level.

We conducted a two-group $t$-test for degree of concretization, with degree of commitment as the grouping variable. A $t$-value of 3.83 shows that the greater the concretization, the greater are the chances of commitment.

We added both the degree of creativity and the degree of concretization as independent variables in the model for commitment. The degree of creativity was insignificant, but concretization was significant $(\alpha=10)$. The odds ratio was 1.5 . Given the difficulty of interpreting the odds ratio for a continuous variable, we conducted the following analysis: we dichotomized both the creativity and the concretization variables to encompass approximately 50 percent in each category. We calculated the probability of 
TABLE 2

Constructs and Cronbach's alphas

\begin{tabular}{|c|c|}
\hline Construct $^{\mathrm{a}}$ & Item \\
\hline Expertise & $\begin{array}{l}\text { 1. People in my profession who have been formally trained as I have and have as many years of work experience are con- } \\
\text { sidered experts. } \\
\text { 2. I consider myself an expert in my field. } \\
\text { 3. Others within the company I work for consider me an expert in my field. }\end{array}$ \\
\hline Thinking style & $\begin{array}{l}\text { 1. In forming this idea, I used concepts that were unrelated to the problem and applied them in new ways. } \\
\text { 2. I used materials around me and made something unique out of them. } \\
\text { 3. I integrated concepts from different fields. } \\
\text { 4. In thinking about this idea, I followed a set routine. } \\
\text { 5. I used the most straightforward approach I could think of to come up with this idea. } \\
\text { 6. My thought process was more logical than intuitive. }\end{array}$ \\
\hline Failure value & $\begin{array}{l}\text { 1. Even though my idea might not have worked, I believed something could still be learned. } \\
\text { 2. If my idea did not work, others would consider my efforts as being futile. (Reverse scored) } \\
\text { 3. If this idea failed, others would appreciate knowing what contributed to its lack of success. }\end{array}$ \\
\hline Work style & $\begin{array}{l}\text { 1. Daydreaming about the remaining unsolved problems was beneficial to the development of this idea. } \\
\text { 2. Sometimes while I worked on other tasks, I found that I was able to think of possible solutions to problems associated } \\
\text { with my idea. } \\
\text { 3. It was not necessary for me to insulate myself from other people while developing this idea. (Reverse scored) } \\
\text { 4. Being around people sometimes hindered me developing this idea. } \\
\text { 5. As I worked on this idea, I frequently needed to be alone. }\end{array}$ \\
\hline Intrinsic motivation & $\begin{array}{l}\text { 1. Curiosity was the driving force behind what I did. } \\
\text { 2. I enjoyed working on this idea, because it was so absorbing that I forgot about everything else. } \\
\text { 3. The complexity of the problem/issue motivated me to formulate and develop this idea. }\end{array}$ \\
\hline Credibility & $\begin{array}{l}\text { 1. Because of the position I hold within the organization, I was able to pursue this idea. } \\
\text { 2. Others within the company I work for consider me an expert in my field. } \\
\text { 3. Being associated with at least one successful idea in my company increased my credibility as I worked on this idea. }\end{array}$ \\
\hline $\begin{array}{l}\text { Formal organizational } \\
\text { culture }\end{array}$ & $\begin{array}{l}\text { 1. Knowing that a rewards program was in place encouraged me to develop this idea. } \\
\text { 2. If my idea proved successful, my efforts would be recognized through the company's rewards program. } \\
\text { 3. The incentives offered for the development of ideas were not worth the effort. (Reverse scored) } \\
\text { 4. My company did not have any problems with me taking the time I needed to work on this idea. } \\
\text { 5. Working on my idea during regular work hours was frowned upon. (Reverse scored) } \\
\text { 6. My other activities took too much time away from the development of this idea. (Reverse scored) }\end{array}$ \\
\hline $\begin{array}{l}\text { Access to relevant and } \\
\text { diverse knowledge }\end{array}$ & $\begin{array}{l}\text { 1. While working on this idea, I consulted freely with colleagues within or outside of my department. } \\
\text { 2. Although my project may not have been work related, people inside and outside of my department were willing to } \\
\text { help me. } \\
\text { 3. Despite being in other functional areas, the people I asked for help were able to provide whatever I needed. }\end{array}$ \\
\hline Organizational resources & $\begin{array}{l}\text { 1. Owing to a lack of resources, my idea could not be properly developed. (Reverse scored) } \\
2 \text {. I could use the organization's resources, in whatever way I wanted to, to develop my idea. } \\
\text { 3. There were no restrictions regarding what resources I used in the development of my idea. }\end{array}$ \\
\hline Visionary & $\begin{array}{l}\text { 1. Someone with more power within the organization promoted my idea to the decision-making committee. } \\
\text { 2. Without the help of influential members within the organization, my idea would have been rejected outright by the deci- } \\
\text { sion-making body. } \\
\text { 3. Someone "higher up" within the organization was committed to seeing my idea developed as fully as possible. }\end{array}$ \\
\hline $\begin{array}{l}\text { Negative conseq } \\
\text { of creation }\end{array}$ & $\begin{array}{l}\text { 1. Owing to the innovativeness of this idea, substantial investments are needed to develop it further. } \\
\text { 2. Because this idea was more unique than were others in the past, the process typically followed cannot be used to } \\
\text { develop it further. } \\
\text { 3. Despite the originality of this idea, little or no organizational change will be required to accommodate its further devel- } \\
\text { opment. (Reverse scored) }\end{array}$ \\
\hline Creativity (o & $\begin{array}{l}\text { 1. This idea was very different from others developed in the past by this division. } \\
\text { 2. The idea included some new aspects compared with previous other ideas addressing this issue. } \\
\text { 3. How would you rate the creativity level of this new product idea? } \\
\text { 4. Compared with my previous, similar ideas, at least some parts of this one were daring, risky, or bold. } \\
\text { 5. This idea was innovative. } \\
\text { 6. The idea broke some of the "rules of the game" within the market or product category. }\end{array}$ \\
\hline Concretization $(\alpha=.75)$ & $\begin{array}{l}\text { 1. Having access to the organization's strategic plan and vision helped me frame this idea with respect to the organiza- } \\
\text { ton's business needs. } \\
\text { 2. While working on this idea, I ensured it satisfied the technological criteria established by my company. } \\
\text { 3. I evaluated my idea with respect to the company's business portfolio. } \\
\text { 4. I used the company's guidelines to help me develop this idea so that it satisfied at least one of the company's business } \\
\text { needs. } \\
\text { 5. It was necessary for me to consistently evaluate my idea with respect to the organization's strategy. } \\
\text { 6. With the help of a person or a department within the company, I was able to develop this idea so that it addressed a busi- } \\
\text { ness need of the company. }\end{array}$ \\
\hline
\end{tabular}

a. Indicators are formative for all constructs except for the two dependent variables. For these two constructs, the indicators are reflective, and thus we show Cronbach's alphas. 
TABLE 3

Factors Influencing Degree of Creativity, Concretization, and Commitment

\begin{tabular}{|c|c|c|c|}
\hline Variable $^{a}$ & Degree of Creativiry ${ }^{b}$ & Degree of Concretization ${ }^{c}$ & Degree of Commitment \\
\hline Expertise & $\beta=.18^{*}$ & & \\
\hline Thinking style & $\beta=.39 *$ & & \\
\hline Failure value & $\beta=.12^{*}$ & & \\
\hline Working style & $\beta=.08$ & & \\
\hline Intrinsic motivation & $\beta=.15^{*}$ & $\beta=-.03$ & \\
\hline Formal organization culture & $\beta=-.09$ & $\beta=.20^{*}$ & $\beta=.28^{*}$ \\
\hline Access to relevant and diverse knowledge & & $\beta=.35^{*}$ & \\
\hline Access to resources & & $\beta=.17^{*}$ & \\
\hline Credibility & & $\beta=.05$ & $\beta=.21^{*}$ \\
\hline Visionary & & & $\beta=.18^{*}$ \\
\hline Consequences of creation & & & $\beta=-.31^{*}$ \\
\hline
\end{tabular}

a. All relationships are hypothesized to be positive.

b. Adjusted $R_{2}^{2}=.22(n=144)$.

c. Adjusted $R^{2}=.27(n=144)$.

d. Adjusted $R^{2}=.17(n=139)$.

* Significant at $\alpha=.10$.

high commitment for each of the four scenarios of lowlow, high-low, low-high, and high-high for creativity and concretization, respectively. The estimated probabilities were $.36, .38, .58$, and .6 , respectively. These numbers show that concretization essentially influences commitment.

\section{MANAGERIAL IMPLICATIONS AND DIRECTIONS FOR FUTURE RESEARCH}

\section{Managerial Impllcations}

A macro contribution of this research for managers is the explication and validation of the concept of concretization. The driving role of framing in concretization makes the idea fruition process not only effective by preventing ideas from being dropped but also efficient by guiding the kind of development that occurs. We found that organizational variables, not individual-level variables, influence concretization. This finding points to the critical role of the organization in harnessing creative ideas. In addition, we highlighted several other variables that affect idea creation and commitment. As we show below, our use of the componential theory of creativity to identify individual-level variables points to several controllable factors that managers can leverage to enhance the innovation of the organization.

Organizations might consider keeping their experts at the cutting edge. As our results reveal, expertise is a significant factor in creativity. Sending individuals to state-ofthe-art seminars, training programs, and conferences as a reward for their creativity might increase the positive impact. First, it will help keep the staff current, and second, such rewards will not be considered "bribes." Individuals can be trained in lateral thinking, failure value, and work styles (e.g., stepping away from the problem and people).
Organizations can also aid in isolation. The result that intrinsic motivation is a key for creativity provides important managerial implications too. Managers should attempt to hire the right kind of individuals for the job, namely, individuals who seek the job because of its inherent qualities. True innovators innovate because of their love of the task. Indeed, as the negative coefficient for formal organizational culture shows, individuals may frown on extrinsic rewards.

Our findings when we combine the results from intrinsic motivation and access to relevant and diverse knowledge have notable managerial implications. Intrinsic motivation implies that idea originators find the work fun, and innovators want to keep it that way. That they need cooperation from other individuals in different departments entails requiring some ties with them. For the work to continue to be fun, such ties should be the ones the idea originators choose to form. Therefore, they must be informal. Because organizations cannot legislate ties of friendship and trust across departments, they should facilitate such social interaction across departments. Such facilitation can result in ties ultimately being formed. Organizations can also publicize and promote key individuals as visionaries to potential idea generators, so that innovators know who to consult when the time comes. Finally, organizations can take steps to mitigate the perception of negative consequences of the creation. Focusing on and thinking about potential consequences would identify solutions that could, in turn, minimize the negative consequences and allow organizations to commit to more ideas.

\section{Directions for Future Research}

A positive aspect of our design is that organizations across a variety of industries can be included in the sample 
cost-effectively, but the inherent design of this study is such that the models' goodness of fit will be poor. The study takes one data point in an organization and relates it to individual and organizational factors. Thus, the error associated with such a design will be high. It might be insightful for future research to study several ideas from many individuals within an organization. The findings from one organization could be compared with those of another organization that is different on the innovation dimension but is in the same industry. Several such matched pairs could be studied. Another reason we did not attain high $R^{2} \mathrm{~s}$ is that the hypotheses proposed and tested an ideal model for idea fruition. It is likely that many organizations are not quite efficient yet in this area.

The effect of extrinsic rewards on creativity and concretization should be studied further. Future research could design a study to test the effects of intrinsic and extrinsic motivation specifically. Although we took care to generate and study ideas at all levels of creativity by asking respondents to discuss the most recent idea, the sample provided ideas that were quite high on the Creativity Scale (mean $=5.8$ ). A reason for this might be that individuals like to talk about good ideas only. New studies should be designed to analyze better the interaction among the three processes of creation, concretization, and commitment. Are creative ideas more or less likely to receive commitment? Are there organizational factors that moderate such a relationship? Is concretization always more difficult for more creative ideas? Is it more efficient and effective to formalize the process of concretization rather than allowing it to be in the informal domain? Can it be formalized? Should organizations focus on capturing ideas early, or should they allow the informal system to nurture and develop them before formally reining them in? Because there are advantages to both routes, when is one more appropriate than the other? These are some of the questions that future research could address.

\section{ACKNOWLEDGMENTS}

Please send all correspondence to Rajiv Grover. A research grant from the Center of Marketing Studies, Terry College of Business, University of Georgia is gratefully acknowledged. Both authors contributed equally to the project.

\section{NOTES}

1. Although formal teams can be created for idea generation as Sethi, Smith, and Park (2001) discussed, solely relying on such an approach ignores hundreds of ideas that are generated by individuals in organizations (Amabile, Conti, Coon, Lazenby, and Herron 1996; Rossman 1964; Woodman et al. 1993).
2. Isolation and incubation can be operationalized individually. However, because these constructs are conceptually related, we treat them as one. Because of the lack of items, we cannot split them herein. This is something that future research in this area can address.

3. Although intrinsic motivation has been related to creativity earlier (e.g., Andrews and Smith 1996), we propose this as a hypothesis and test it herein because we use intrinsic motivation as a factor for concretization as well. We want to capture any differential impact of this variable on creativity and concretization.

4. We checked for other indicators of multicollinearity (i.e., standard errors and sensitivity of the significance of parameters to observations and addition/deletion of variables). There was no indication of multicollinearity.

5. The idea originators were asked to identify the individual who made the go/no-go decision for the idea's advancement. The decision maker was asked several questions, including the level of creativity (six items) and the level of commitment. We did this to minimize any bias resulting from idea originators' evaluating their own ideas (single-source or subjectivity bias). A paired $t$-test on creativity rating and a chi-square test on commitment rating between the two sources showed that idea originators and decision makers were consistent in their evaluations.

\section{REFERENCES}

Amabile, Teresa M. 1983. The Social Psychology of Creativity. New York: Springer-Verlag.

1998. "How to Kill Creativity." Harvard Business Review 76 (5): 76-87.

Regina Conti, Heather Coon, Jeffrey Lazenby, and Michael Herron. 1996. "Assessing the Work Environment for Creativity." Academy of Management Joumal 39 (5): 1154-1184.

- Karl Hill, Beth Hennessey, and Elizabeth Tighe. 1994. "The Work Preference Inventory: Assessing Intrinsic and Extrinsic Motivational Orientations." Joumal of Personality and Social Psychology 66 (5): 950-967.

Andrews, Jonlee and Daniel Smith. 1996. "In Search of the Marketing Imagination: Factors Affecting the Creativity of Marketing Programs for Mature Products." Journal of Marketing Research 33 (2): 174187.

Bereiter, Carl and Marlene Scardamalia. 1993. Surpassing Ourselves: An Inquiry Into the Nature and Implications of Expertise. Chicago: OpenCourt.

Bhardwaj, Gaurab, Rajiv Grover, and Ravindranath Madhavan. 2005. "The Role of Social Capital in the New Product Development Process." Working paper. University of Georgia, Athens.

Chandy, Rajesh and Gerard Tellis. 1998. "Organizing for Radical Product Innovation: The Overlooked Role of Willingness to Cannibalize." Journal of Marketing Research, 35 (November): 474-487.

Collins, James and Jerry Porras. 1994. Built to Last: Successful Habits of Visionary Companies. New York: HarperBusiness.

Cooper, Robert and Elko Kleinschmidt. "An Investigation Into the New Product Process: Steps, Deficiencies, and Impact." Journal of Product Innovation Management 3 (2): 71-85.

Crawford, Merle C. 1994. New Products Management. Burr Ridge, IL: Irwin.

Csikszentmihalyi, Mihaly. 1990. Flow: The Psychology of Optimal Experience. New York: HarperCollins.

de Bono, Edward. 1971. "Creativity and Lateral Thinking." In Creativity in Communications. Ed. Robert Adams. Greenwich, CT: New York Graphic Society, 24-29.

Deshpandé, Rohit and Fredrick Webster Jr. 1989. "Organizational Culture and Marketing: Defining the Research Agenda." Journal of Marketing 53(1): 3-15.

Dutton, Jane E. and Susan J. Ashford. 1993. "Selling Issues to Top Management." Academy of Management Review 18 (3): 397-428.

- Regina M. O'Neill, and Katherine A. Lawrence. 2001. "Moves That Matter: Issue Selling and Organizational Change." Academy of Management Journal 44 (4): 716-736. 
Eisenhardt, Kathleen. 1989. "Building Theories From Case Study Research." Academy of Management Review 14 (4): 532-550.

Glaser, Barney G. and Anselm L. Strauss. 1967. The Discovery of Grounded Theory: Strategies of Qualitative Research. London: Wiedenfeld and Nicholson.

Golder, Peter and Gerald Tellis. 1993. "Pioneer Advantage: Marketing Logic or Marketing Legend." Journal of Marketing Research 30 (2): 158-170.

Grant, Robert. 1995. Contemporary Strategy Analysis. Cambridge, MA: Blackwell.

Griffin, Abbie and John Hauser. 1996. "Integrating R\&D and Marketing: A Review and Analysis of the Literature." Journal of Product Innovation Management 13 (3): 191-215.

Gupta, Ashok K., S. P. Raj, and David Wilemon. 1986. "A Model for Studying R\&D-Marketing Interface in the Product Development Process." Journal of Marketing 50 (April): 7-17.

Holland, John and Leonard Baird. 1968. "The Preconscious Activity Scale: The Development and Validation of an Originality Measure." Journal of Creative Behavior 2 (3): 217-225.

Holt, Mnut. 1988. "The Role of the User in Product Innovation." Technovation 7 (4): 249-258.

Joseph, Benoy. 1982. "The Credibility of Physically Attractive Communicators: A Review." Joumal of Advertising 11 (3): 15-24.

Kahle, Lynn and Pamela Homer. 1985. "Physical Attractiveness of the Credibility Endorser: A Social Adaptation Perspective." Journal of Consumer Research 11 (4): 954-961.

Kanter, Rosabeth Moss, John Kao, and Fred Wiersema. 1997. Breakthrough Thinking at $3 M$, duPont, GE, Pfizer, and Rubbermaid: Innovation. New York: HarperCollins.

Kassarjian, Harold. 1977. "Content Analysis in Consumer Research." Journal of Consumer Research 4 (1): 8-17.

Khurana, Anil and Stephen Rosenthal. 1998. "Towards Holistic 'Front Ends' in New Product Development." Journal of Product Innovation Management 15 (1): 57-74.

Koestler, Arthur. 1964. The Act of Creation. New York: Dell.

Lynn, Gary, Mario Mazzuca, Joseph Morone, and Albert Paulson. 1996. "Learning Is the Critical Success Factor in Developing Truly New Products." Research-Technology Management 41 (3): 45-51.

Madhavan, Ravindranath and Rajiv Grover. 1998. "From Embedded Knowledge to Embodied Knowledge: New Product Development as Knowledge Management." Joumal of Marketing 62 (4): 1-12.

McKenzie, Craig. 2003. "Judgment and Decision Making." In Handbook of Cognition. Eds. K. Lamberts and R. L. Goldstone. London: Sage, 321-332.

Menon, Anil, Sundar Bharadwaj, Phani Tej Adidam, and Steven W. Edison. 1999. "Antecedents and Consequences of Marketing Strategy Making: A Model and a Test." Journal of Marketing 63 (2): 18-40.

Moore, Arthur. 1969. Invention, Discovery, and Creativity. New York: Doubleday.

Moorman, Christine. 1995. "Organizational Market Information Processes, Cultural Antecedents and New Product Outcomes." Journal of Marketing Research 32 (August): 318-335.

Nayak, P. Ranganath and John Ketteringham. 1986. Breakthroughs. Toronto: Collier Macmillan Canada.

Patton, Michael Quinn. 1990. Qualitative Evaluation and Research Methods. $2 \mathrm{~d}$ ed. Newbury Park, CA: Sage.

Rossman, Joseph. 1964. Industrial Creativity: The Psychology of the Inventor. New York: University Books.

Ruscio, John, Dean Whitney, and Teresa Amabile. 1998. "Looking Inside the Fishbowl of Creativity: Verbal and Behavioral Predictors of Creative Performance." Creativity Research Journal 11 (3): 4243-4263.
Sethi, Rajesh, Daniel C. Smith, and C. Whan Park. 2001. "CrossFunctional Product Development Teams, Creativity, and the Innovativeness of New Consumer Products." Journal of Marketing Research 38 (February): 73-85.

Simon, Herbert. 1986. "What We Know About the Creative Process." In Frontiers in Creative and Innovative Management. Ed. Rober Kuhn. Cambridge, MA: Ballinger, 3-20.

Smircich, Linda. 1983. "Concepts of Culture and Organizational Analysis." Administrative Science Quarterly 28 (3): 339-358.

Stein, Barry S. 1989. "Memory and Creativity." In Handbook of Creativ. ity. Eds. J. A. Glover, R. R. Ronning, and C. R. Reynolds. New York: Plenum, 163-176.

Sternberg, Robert. 1985. "Implicit Theories of Intelligence, Creativity, and Wisdom." Journal of Personality and Social Psychology 49 (3): 607-627.

and Todd Lubart. 1991. "An Investment Theory of Creativity and Its Development." Human Development 34:1-31.

Van de Ven, Andrew. 1986. "Central Problems in the Management of Innovation." Management Science 32 (5): 590-607.

Woodman, Richard, John Sawyer, and Ricky Griffin. 1993. "Toward a Theory of Organizational Creativity." Academy of Management Review 18 (2): 293-321.

Yenne, Bill and Morton Grosser. 1993. I00 Inventions That Shaped World History. San Francisco: Bluewood Books.

Yin, Robert. 1994. Case Study Research: Design and Methods. 2d ed. Newbury Park, CA: Sage.

Young, James Webb. 1960. A Technique for Producing Ideas. Chicago: Advertising Publications.

Zajonc, Robert B. 1965. "Social Facilitation." Science 149:269-274.

\section{ABOUT THE AUTHORS}

Janice Griffiths-Hemans (janice.griffith-hermans@astrazeneca .com) holds a Ph.D. in business administration (marketing strategy and new product development) and a master's in market research from the University of Georgia, an MBA in marketing from the University of Miami, and a bachelor of science degree in pure and applied chemistry from the University of the West Indies, Jamaica. Janice is currently a Senior Manager of Consumer Insights with Astra Zeneca, Wilmington, Delaware.

Rajiv Grover (rgrover@terry.uga.edu) is the head of the department and holder of the Terry Chair of Marketing at the Terry College of Business, the University of Georgia in Athens, Georgia. $\mathrm{He}$ has received several honors for his research and teaching efforts-the O'Dell award for the Best Paper in the Journal of Marketing Research and the Hugh O. Nourse Outstanding MBA Teacher Award. He has authored the book Theory and Simulation of Market-Focused Management, published by Dryden Press. He is currently editing The Handbook of Marketing Research: Do's and Don'ts, which will be published by Sage Publications. He received his Ph.D. from the University of Massachusetts at Amherst in 1983. 